\title{
A Successful Experience of International Training and Education in Manufacturing
}

\author{
L. Quintino1,2, E. Assunção'1,2, R. M. Miranda ${ }^{3 *}$ \\ ${ }^{1}$ Instituto Superior Técncio, Universidade de Lisboa, Lisbon, Portugal \\ ${ }^{2}$ EWF, European Federation for Welding, Joining and Cutting, Porto Salvo, Portugal \\ ${ }^{3}$ UNIDEMI, Departamento de Engenharia Mecânica e Industrial, Faculdade de Ciências e Tecnologia, Universidade Nova de \\ Lisboa, Caparica, Portugal \\ Email: ${ }^{\star}$ rmmdm@fct.unl.pt
}

How to cite this paper: Quintino, L., Assunção, E., \& Miranda, R. M. (2017). A Successful Experience of International Training and Education in Manufacturing. Creative Education, 8, 24-32.

http://dx.doi.org/10.4236/ce.2017.81003

Received: November 30, 2016

Accepted: January 10, 2017

Published: January 13, 2017

Copyright (C) 2017 by authors and Scientific Research Publishing Inc. This work is licensed under the Creative Commons Attribution International License (CC BY 4.0).

http://creativecommons.org/licenses/by/4.0/

\section{Open Access}

\begin{abstract}
The need from industry to have international qualifications was the starting point for creating the training and qualification system built by the European Welding Federation (EWF) for professionals in welding technology from level 2 up to 7. This paper describes this system, which started in 1992 and has successfully amplified mostly because it is supported by a robust and transparent quality system developed and implemented which is recognized by the complete chain of individuals and organizations involved, from training institutions, national certification bodies, companies, trainers and trainees. It is now implemented in 44 countries and recognized worldwide. A recent experience of collaboration between a national body and a university to award a master degree is also discussed. This is well in line with EU recommendations for the interchange between training and educational systems.
\end{abstract}

\section{Keywords}

Training System, Qualification System, Learning Outcome, ECVET, Welding

\section{Introduction}

Education and training are widely recognized as a strength for individuals, companies and countries and in the past decades an increasing number of high quality certificates and diplomas have been granted to individuals, awarded by a range of bodies, organizations and companies representing a wide variety of stakeholders and interests. However, most of these diplomas are awarded outside an international recognition system and this is of major concern to Europe.

Europe has, as one of its flagships for the framework 2014/2020, the need to harmonize qualifications at an international level, facilitating mobility within the 
European space, or even to other regions in the world. Qualifications play a key role of public interest, such as health and safety and quality assurance requirements, meeting the needs and controlling access to professions and occupations, but, most importantly, they facilitate employability and they constitute a competitive advantage for companies, especially the ones acting in different countries (CEDEFOP, 2012).

In the globalization era, individuals need to use their qualifications in more than one country and employers need to be able to evaluate the level of skills and competences their employees possess. The international dimension and the position of education in the global ground are given great emphasis in international, national and institutional speeches than ever before. It helps students to develop an international awareness and intercultural skills.

This trend is particularly visible in sectors like transport where international organizations, sectoral bodies and multinational companies already play a key role in defining and awarding qualifications and thus, in setting the requirements for skills and competences.

Additionally, throughout his (her) life, an individual can be granted academic qualifications as well as training qualifications and there is no system to recognize and integrate the two systems.

European universities recognize academic degrees around Europe based on the European Credit Transfer System (ECTS), while a similar system for Vocational Education and Training (ECVETS) is being developed and correspondence between education and training systems is expected (ECVET, 2016).

The European Qualifications Framework (EQF) for lifelong learning provides a common referencing for comparison between national qualifications frameworks. It has a set of tools that allow to decode different qualifications systems and their levels (Tremblay et al., 2012).

The European Credit system for Vocational Education and Training (ECVET) is a technical framework for transfer, recognition and accumulation of an individual's knowledge, skills and competences aiming at achieving a qualification through documentation of competences. Therefore the ECVET framework can be used in mobility where learners are to achieve their competences, and get them documented, assessed, validated and recognized in their home country as a part of a qualification. This makes it more attractive to work or study in other countries. ECVET aims at providing greater comparability between the various vocational education and training (VET) systems across Europe in a similar way as the ECTS role for University education.

The ECTS system was driven by the well-known Bologna Declaration and is based on the total number of working hours a student has to devote to successfully accomplish a module at the university in the first or second levels of education, that is, level 7 of European qualification. The establishment of a correlation between the two credit transfer systems would be beneficial for the mobility from vocational training in professional schools to formal education in universities and these would fulfill a relevant gap to increase mobility as far as education and training is concerned. 
This paper describes the international training and qualification system built by the European Welding Federation (EWF) for professionals in the fields of welding technology which was ahead of EU recommendations for international recognition of professional qualifications, and a pilot experience of interchange between training and educational systems.

\section{The EWF System}

Increasing the EU competitiveness in Manufacturing is one of the objectives defined for the period 2014-2020, which is expected to increase employment and turnover of European companies. Within the manufacturing sector, welding is, eventually, the most used technology with recognized importance in terms of both employment and added value.

A comprehensive study conducted in Germany in 2013 based on data collected in European organizations, statistical analysis and modelling, led to results that show that the total added value generated by European joining industry is around 66 Billion Euros per year and estimates that just over 1.2 million people work in welding and related technologies. Welding technology is involved in most manufactured products or components, from transport industry, to energy production, from macro- to microscale components (Moos \& Janßen-Timmen, 2013).

If a weld is not properly performed, catastrophic failure of the welded construction may occur with serious damage to people and significant economic losses. It has been estimated that the cost of repairing an unacceptable weld can cost 5 to 6 times the cost of welding if correctly in the first time (Baur \& Wee, 2015). Safety and profit depend then on a good technical control of welding operations where personnel knowledge, competence and skills play an important role. Key staff in all welding related activities need to have an appropriate level of competence in welding technology and its application. In addition to employing competent and tested welders, companies manufacturers should ensure that engineers, designers and technicians who deal with welding issues at all levels possess relevant competences. This requirement is inscribed in the standard EN ISO 14731 "Welding Coordination-Tasks and Responsibilities" which specifies that people with welding related responsibilities have to be able to demonstrate that they are competent to carry out those responsibilities. Furthermore, in order to comply with EN ISO 3834 "Quality requirements for fusion welding of metallic materials", it is necessary also to comply with EN ISO 14731.

In 1990, the member countries of EU where welding courses were offered started a process of harmonization of the content of education and the implementation in terms of course's syllabus and hours of training allocated to each module. Each course was organized in modules, each one organized in content units described by a relatively exhaustive number of syllabus. By the use of a single syllabus for each level of training course and a harmonized system for examinations, the same qualification could be awarded in any country.

This nucleus of organizations progressed to a qualification system set in 1992 
for welding engineers, welding inspectors and welders. These qualifications formed the basis of the widely accepted International Diplomas.

Certification of welding personnel started to be addressed by European Welding Federation (EWF) about 15 years ago due to the requirement of industry in having staff not only qualified but also certified for the job. With the European enlargement other country members were associated to this group.

An organisation, recognised by the EWF national member society, is appointed as the Authorised National Body (ANB) for the supervision of the entire system comprising training, qualification and certification of personnel in each country. Representatives from these ANBs form the operational management within the EWF, and they nominate and approve Lead Assessors and Peer Assessors who ensure conformity of each ANB to agreed Rules. In general terms, ANBs are responsible at the national level for:

1) Assessing and monitoring of Approved Training Bodies (ATBs).

2) Conduct examinations.

3) Assess applicants for certification.

4) Issue of Diplomas and Certificates.

With this robust system and after negotiations with the International Institute of Welding (IIIW) that had a similar system, non-European countries were added, and the network comprises, at the moment, 46 countries (Figure 1) using the EWF/IIW qualifications and certifications, in a total with $44 \mathrm{ANBs}, 683$ ATBs, and 26 ANBCC. The network also includes 55,000 companies worldwide.

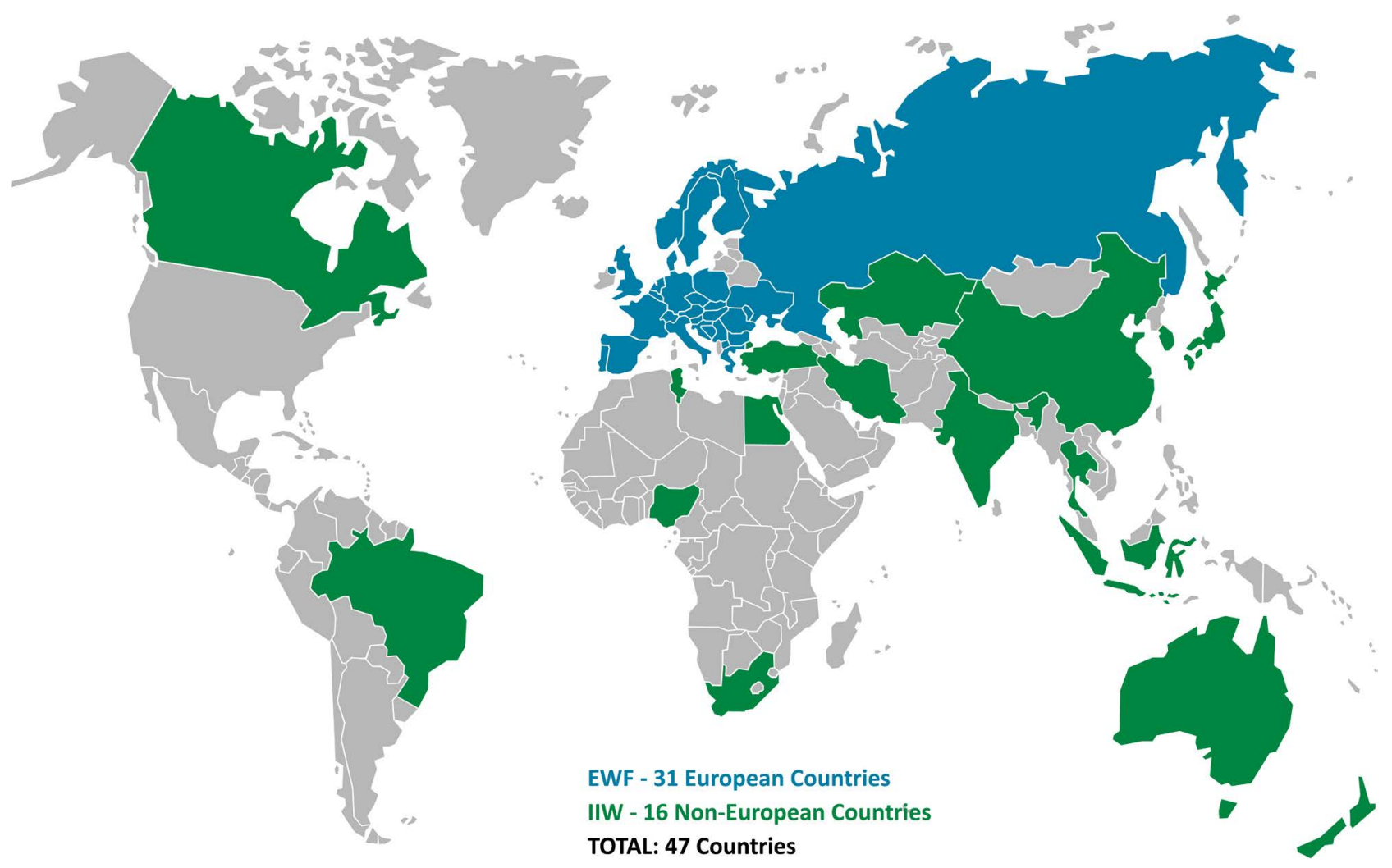

Figure 1. Geographical distribution of countries using the international harmonized system for qualification of welding personnel. 
The Authorised Training Bodies are approved and supervised by the ANBs for implementing the IIW/EWF Qualification courses, which combine both supporting knowledge and application experience, in a close relation with industry and their needs. Special courses were developed providing a specific education on emerging technologies, as for instances in laser welding or adhesive bonding. Figure 2 depicts the number of Diplomas and Certificates awarded since the systems were introduced.

The International Training and Qualification system is used in Europe and other world regions (Kirsch \& Beernaert, 2011) and comprises Education, Examination and Qualification Guidelines for different professional levels listed below.

1) Personnel with Responsibility for Welding Coordination (includes the International/European Welding Engineer-IWE/EWE;

2) International/European Welding Technologist-IWT/EWT;

3) International/European Welding Specialist-IWS/EWS;

4) International/European Welding Practitioner-IWP/EWP;

5) International/European Welding Inspection Personnel-IWIP/EWIP;

6) International/European Welder-IW/EW.

Blended learning options are admitted facilitating education in different countries, mobility and long life learning.

Figure 3 shows a scheme of the structure of the entire Qualification levels for both the EWF and IIW systems showing a good compatibility.

The EWF training system is based on modules and offer different pathways to a life-long learning process starting on the welder level up to Technologist but

200000

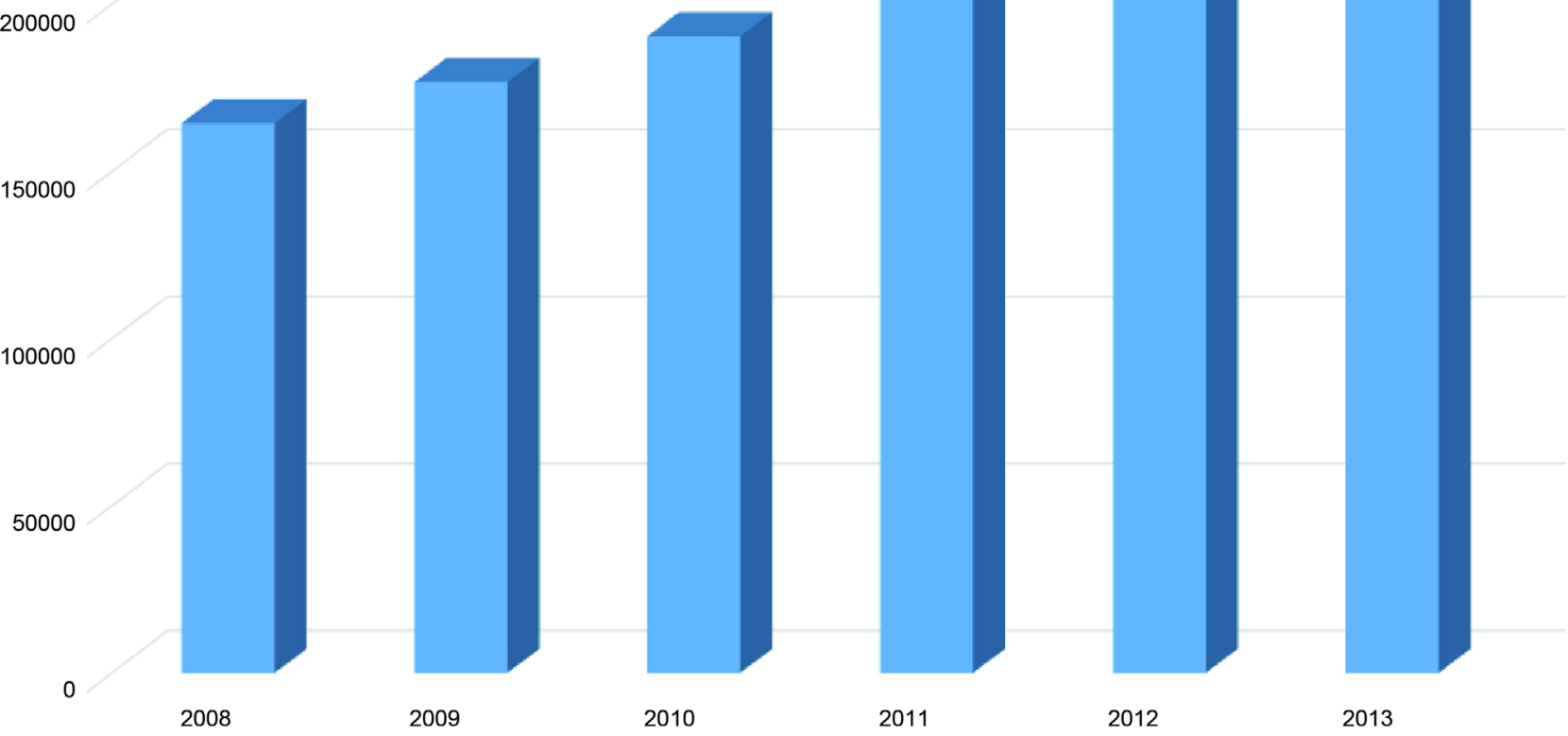

Figure 2. IIW and EWF diplomas/certificates awarded since 2008. 
also gives a pathway for progression from one qualification level to another. Figure 4 gives an overview on the learning pathways that individuals may undertake matching qualifications and career progression in a LLL progress.

An important aspect that made this system so widely accepted and recognized relies on the system quality evaluation. There is a set of highly qualified quality auditors that perform external audits to both ANBs and ATBs and check the consistency of the full chain from application to diploma issuing, including training and trainees and trainers assessments. The audits closely follow ISO/IEC 17024 standard for all levels of education. The implementation and

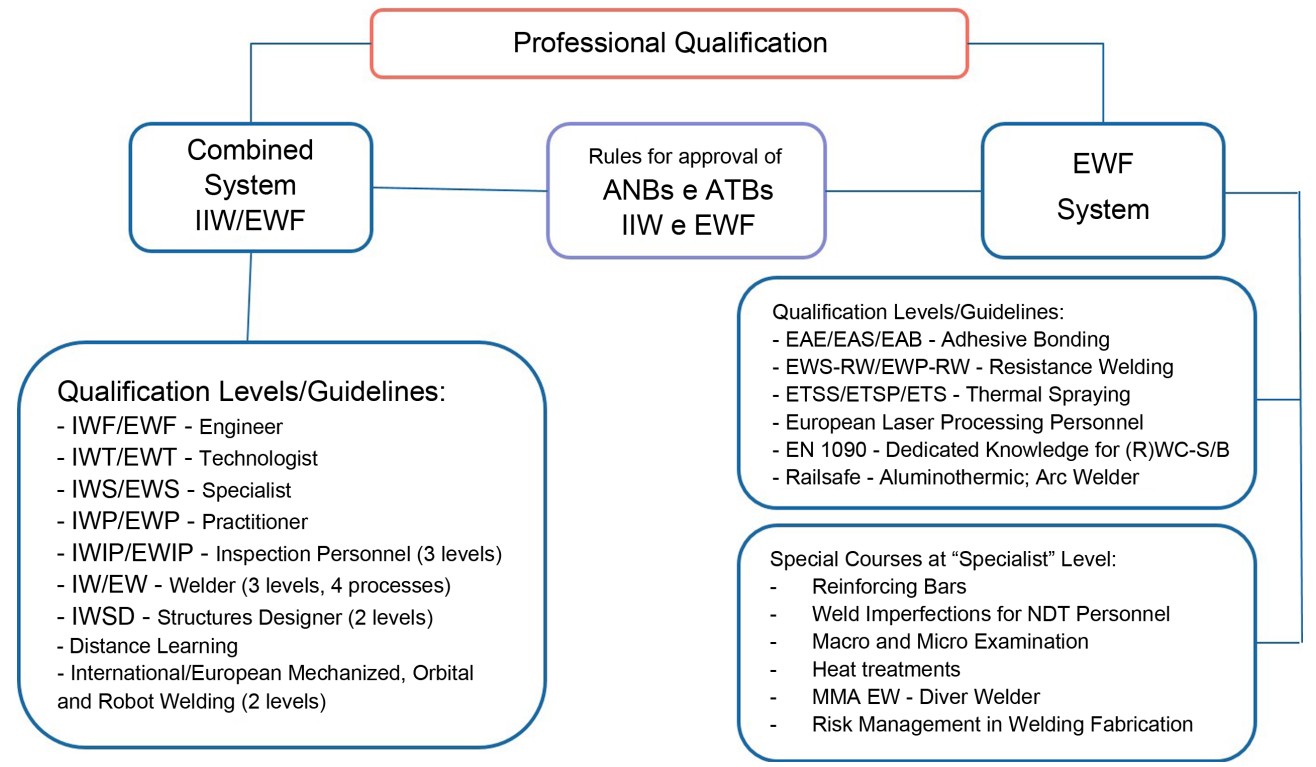

Figure 3. IIW/EWF professional qualification structure.

The IIW/EWF Training System for Welding Personnel

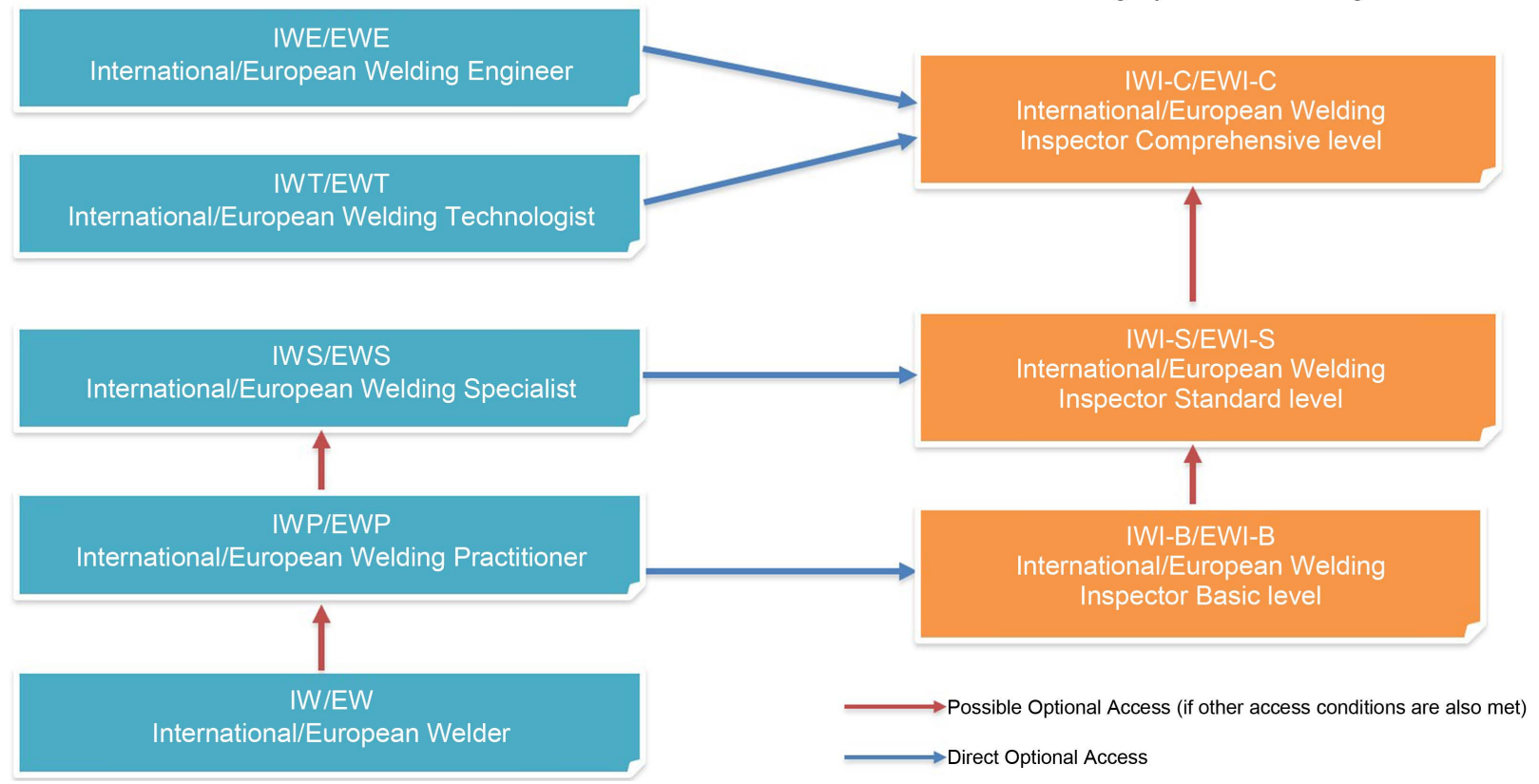

Figure 4. EWF/IIW learning pathways. 
evaluation of this system is crucial for the quality recognition of all international welding community.

\section{Training-Education Mobility}

The mobility from vocational training to formal education is within EU concerns, to allow high levels of education of EU individuals, and increase their mobility and employability in other countries.

The development of short cycle higher education (SCHE) over the past years, as an intermediate degree within the first level in higher education, is a link between secondary and higher education and for many learners is the possibility to access higher education without a previous secondary school degree and is a major element to fulfill the chain of lifelong learning. Recent studies show that all the countries are working at positioning SCHE at level 5 of EQF or their national framework (Quintino et al., 2014). The EWF system organization can allow the recognition of European welding technologist to enter level 5 and continue to SCHE and this is a relevant contribution in individuals valuing.

The admission to welding engineering level is a particular case where it is required the trainee has, at least, a BSc in Engineering, which is level 7 qualification. Recently, a joint collaboration was launched to grant a master degree in welding engineering by University. The University recognized the training provided by and ATB, certified by an ANB as the curricular part of the MSc. The thesis is under responsibility of the University and is supervised by a professor.

Since master programs, at Universities, are organized in ECTSs, a number of credits was attributed to each module as a function of the total number of hours allocated to the student in agreement with ECTS organization. The process was, first, recognized at University Council level and, later, at the government level. Future initiatives as this one are expected in other countries. Since ECVET is mostly focused on learning outcomes there will be a need to correlate these LOs with ECTS, which is already of concern in EU.

The experience can be benchmarked to other areas provided that the courses are modular and there is a transparent quality system implemented known and recognized by all stakeholders.

Introduction of new distance training modules and new/innovative training tools is another challenge taking benefit of information and communication technologies ICT (Quintino et al., 2014). There is a concern to reach more deep knowledge and practical levels, boosting the redesign of the EWF guidelines according to the newest trends and aiming at attracting the youngest generations, whilst upskilling the older and experienced ones.

\section{Future Developments}

The system is under continuous improvement and adjustment to new technologies and learning methods. Examples of new projects being carried out to improve the system include the Rainbow Project aimed at the design of more flexible courses, structured in modules with new learning pathways, based on skills 
demonstration through exams and practical tests.

The organization continuously attempts to keep updated with forefront realities and technologies, as those emerging from Industry 4.0, updating qualifications in welding and joining, developing new ones and adapting training and qualification pathways, assuring access of professionals to updated training, among others.

Slightly ahead, EWF is about to develop projects capable to boost the "next industrial revolution", namely in additive manufacturing and, at the same time, aiming to qualify workman force accordingly in order to allow companies to hire professional profiles ready to be employed.

\section{Conclusion}

The harmonised international EWF/IIW training, qualification and certification systems described provide individuals and companies with a well-recognised training scheme in line with EU concerns as far as VET and LLL are concerned.

These systems have achieved considerable maturity and recognition, and are being continuously improved.

Five main vectors define the strategy of EWF:

- Maintain the training and qualification System updated to comply with technical innovation and industrial demand;

- Develop new qualifications in line with technological and industrial advances;

- Provide a pathway for continuous professional development for welding professionals;

- Create flexible pathways for continuous professional development;

- Assure the quality of the EWF diplomas, by running a rigorous quality assurance system in the countries worldwide using the EWF System.

EWF is currently coordinating a European Funded Project, called RAINBOW, which aims at developing a methodology which will align the International Qualifications of EWF with the European Qualifications Framework, defining a path for other systems to follow.

\section{Disclaimer}

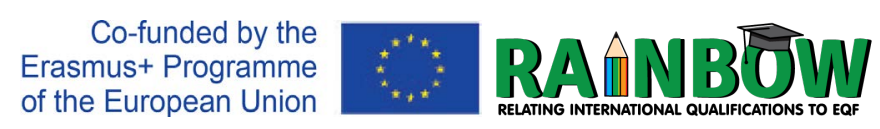

This project has been funded with support from the European Commission. This publication reflects the views only of the author, and the Commission cannot be held responsible for any use which may be made of the information contained therein.

\section{References}

Baur, C., \& Wee, D. (2015). Manufacturing's Next Act.

http://www.mckinsey.com/insights/manufacturing/manufacturings next act

CEDEFOP (2012). The Welding Case. In CEDEFOP, International Qualifications. Lux- 
embourg: Publications Office of the European Union.

ECVET \& EQF with Learning Outcomes (2016). http://www.skillstools.eu/ecvet-eqf

Kirsch M., Beernaert Y., (2011). Short Cycle Higher Education in Europe Level 5: The Missing Link. Belgium: EURASHE.

Moos, W., \& Janßen-Timmen, O. (2013). Macroeconomic and Sectoral Value Added by the Production and Application of Joining Technology in Germany and Europe. Bochum, 20 March 2013

Quintino, L., Ferraz, R., Fernandes, I., \& Assunção, E. (2014). International Harmonised Education and Training in Manufacturing Technology: The Case of Welding. In Proceedings of the 13th International Conference on Education and Educational Technology, Lisbon, 30 October-1 November 2014 (pp. 134-137). Lisbon: World Scientific and Engineering Academy and Society Press.

Tremblay, K., Lalancette, D., \& Roseveare, D. (2012). Assessment of Higher Education Learning Outcomes. Bochum: Ed. OECD.

Submit or recommend next manuscript to SCIRP and we will provide best service for you:

Accepting pre-submission inquiries through Email, Facebook, LinkedIn, Twitter, etc. A wide selection of journals (inclusive of 9 subjects, more than 200 journals) Providing 24-hour high-quality service User-friendly online submission system Fair and swift peer-review system Efficient typesetting and proofreading procedure Display of the result of downloads and visits, as well as the number of cited articles Maximum dissemination of your research work

Submit your manuscript at: http://papersubmission.scirp.org/

Or contact ce@scirp.org 